[Agr. Biol. Chem., Vol. 33, No. 4, p. 592 597, 1969]

\title{
Gibberellins in Immature Seeds of Canavalia
}

\section{Part I. Isolation and Biological Activity of Gibberellins}

$$
\mathrm{A}_{21} \text { and } \mathrm{A}_{22}
$$

\author{
By Noboru Murofushi, Nobutaka Takahashi, Takao Yokota, \\ Jiro Kato*, Yoshitaka Shiotani* and Saburo Tamura \\ Department of Agricultural Chemistry, The University of Tokyo, Tokyo \\ * Department of Biology, University of Osaka Prefecture, Sakai, Osaka \\ Received September 24, 1968
}

\begin{abstract}
Two novel gibberellins, $\mathrm{GA}_{21}$ (I) and $\mathrm{GA}_{22}$ (II), were isolated from immature seeds of sword bean, Canavalia gladiata DC. The isolation procedure of these substances as well as their growth-promoting effects on dwarf maize mutants $d_{1}$ and $d_{5}$, rice, cucumber and dwarf peas (Progress No. 9) are described.
\end{abstract}

Several crystalline gibberellins have been isolated from higher plants and their structures established. Most of them were obtained from immature leguminous seeds. In 1959 Murakami noticed the presence of gibberellin-like substances in immature seeds of sword bean (Canavalia gladiata DC.), ${ }^{1}$ an annual leguminous plant which bears large pods of approximately $30 \mathrm{~cm}$ in length and $5 \mathrm{~cm}$ in width. As preliminarily reported in the previous papers, ${ }^{2,3)}$ we have succeeded in the isolation of two new gibberellins from immature seeds of this plant and determined their structures. In this paper we wish to report the details of their isolation procedure and biological activities.

The acidic fraction of the immature seeds showed a marked growth-promoting effect on dwarf maize mutant $d_{5}$. As illustrated in Fig. 1 , thin layer chromatography (TLC) of this fraction revealed three distinct fluorescent spots, characteristic of gibberellins, under

1) Y. Murakami, Bot. Mag. Tokyo, 72, 36 (1959).

2) S. Tamura, N. Takahashi, N. Murofushi, T. Yokota, J. Kato and Y. Shiotani, Planta, 75, 279 (1967).

3) N. Takahashi, N. Murofushi, T. Yokota, S. Tamura, J. Kato and Y. Shiotani, Tetrahedron Letters, 1967, 4861 . ultraviolet light after spraying with sulfuric acid and heating. On the other hand, bioassay using $d_{5}$ dwarf maize mutant indicated the presence of two gibberellin-like substances corresponding to spots II and III, while spot I scarcely showed any activity. Isolation of the gibberellin-like substances was undertaken according to the procedure illustrated in Fig.

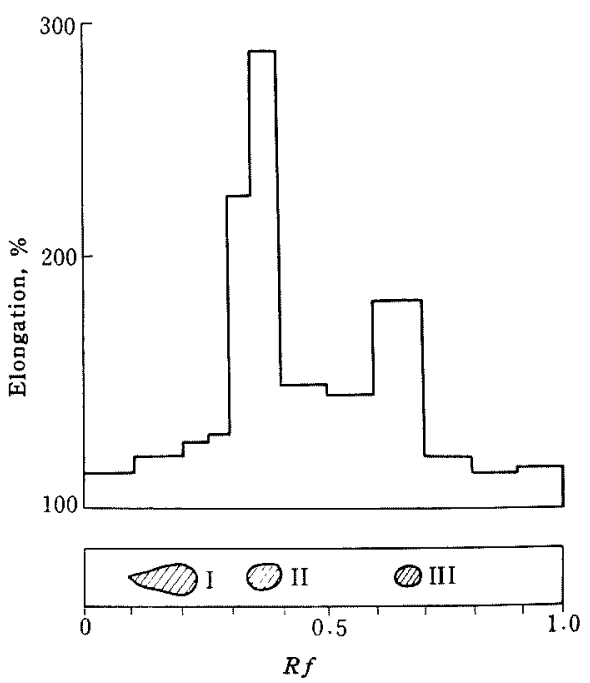

FIG. 1. Thin Layer Chromatography and Bioassay of Crude Extract on Dwarf Maize Mutant $d_{5}$. 


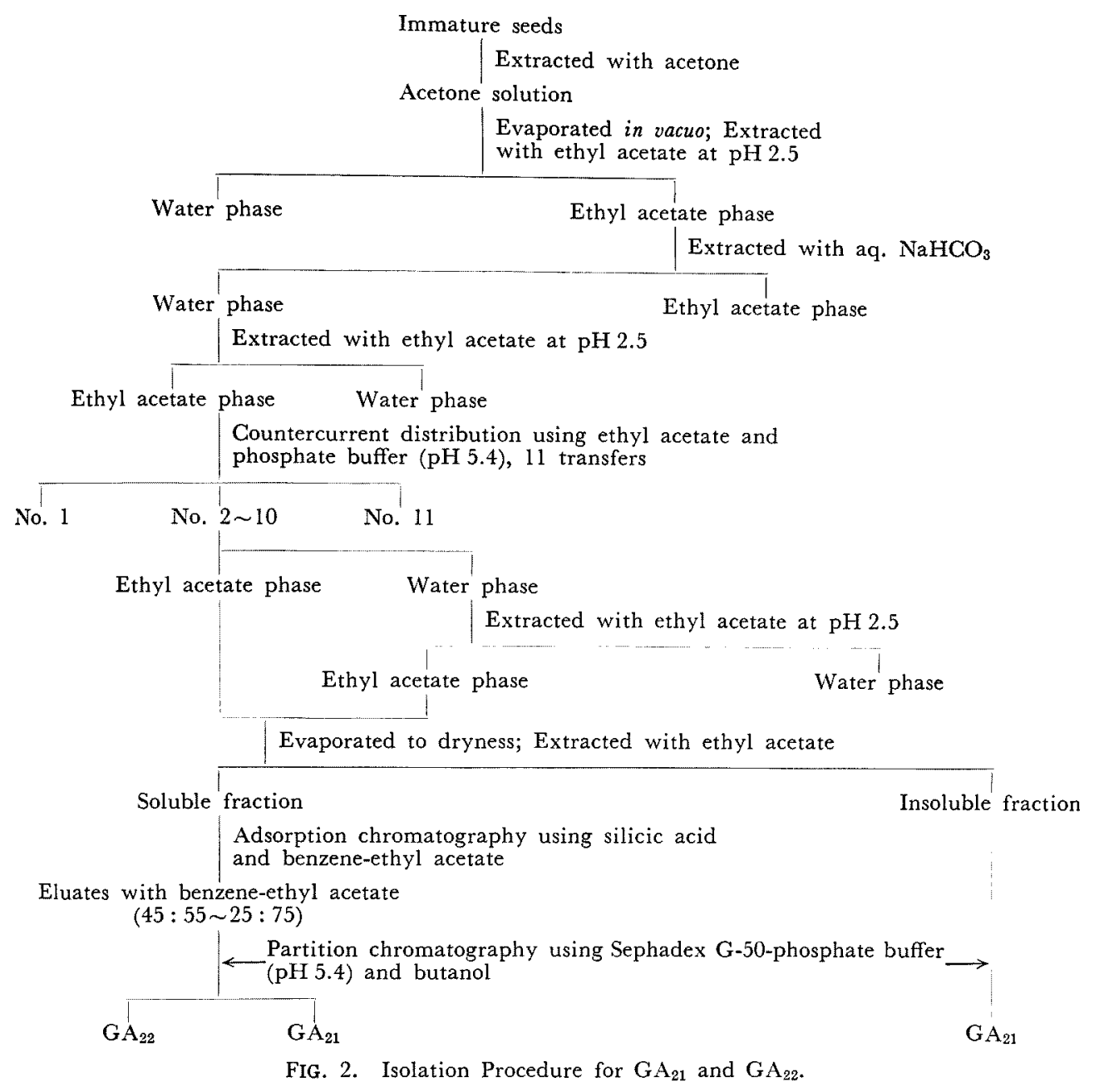

2. At each step of purification, the activity was detected by $d_{\overline{5}}$ bioassay in combination with TLC.

Immature seeds were extracted with acetone using a blender. The ethyl acetate-soluble acidic fraction was obtained by the usual method and applied to countercurrent distribution by the use of ethyl acetate and phosphate buffer ( $\mathrm{pH}$ 5.5) with eleven transfers. Biologically active solid was recovered from fractions No. $2 \sim 10$ and extracted with ethyl acetate to give ethyl acetate-soluble and -in- soluble fractions. The soluble fraction was purified by silicic acid adsorption chromatography. Elution with benzene-ethyl acetate $(80: 20, v / v)$ gave an active principle corresponding to spot III, but it could not be obtained as crystals due to its low content. The eluates with benzene-ethyl acetate (45: $55 \sim 25: 75, v / v)$ contained the substances corresponding to spots $\mathrm{I}$ and $\mathrm{II}$, which were separated as crystals respectively with partition chromatography using butanol and Sephadex G-50 treated with phosphate buffer ( $\mathrm{pH}$ 5.4). 
The ethyl acetate-insoluble fraction mentioned firmed to be new $\mathrm{C}_{19}$ gibberellins on the basis above also afforded the compound corresponding to spot I by partition chromatography conducted in the same manner as for the soluble fraction.

The two substances thus obtained were conof physico-chemical data, behavior on TLC and biological activities, and tentatively named "canavalia gibberellins I and II"," which were afterwards changed to gibberellins $A_{21}$ and $A_{22}\left(G_{21}\right.$ and $\left.G_{22}\right)$ according to the

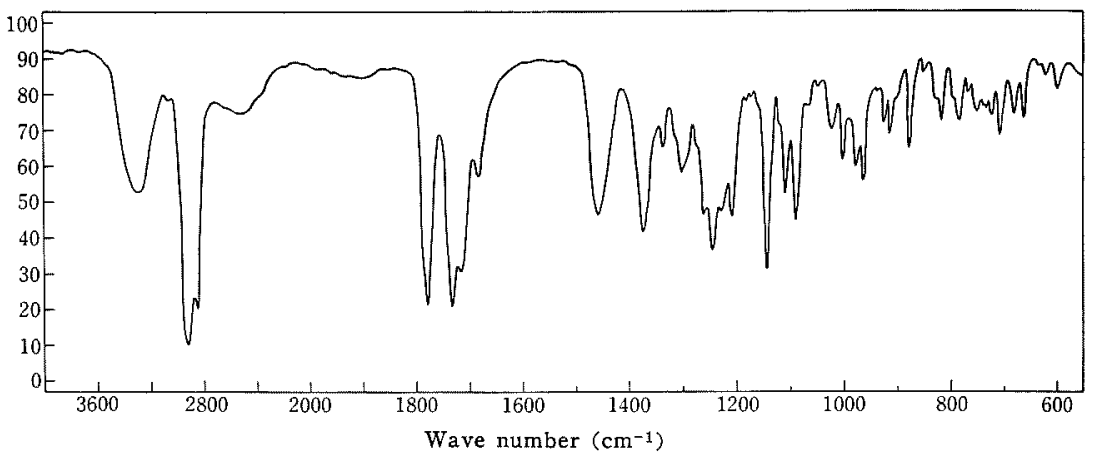

FIG. 3. IR Spectrum of $\mathrm{GA}_{21}$ (nujol).

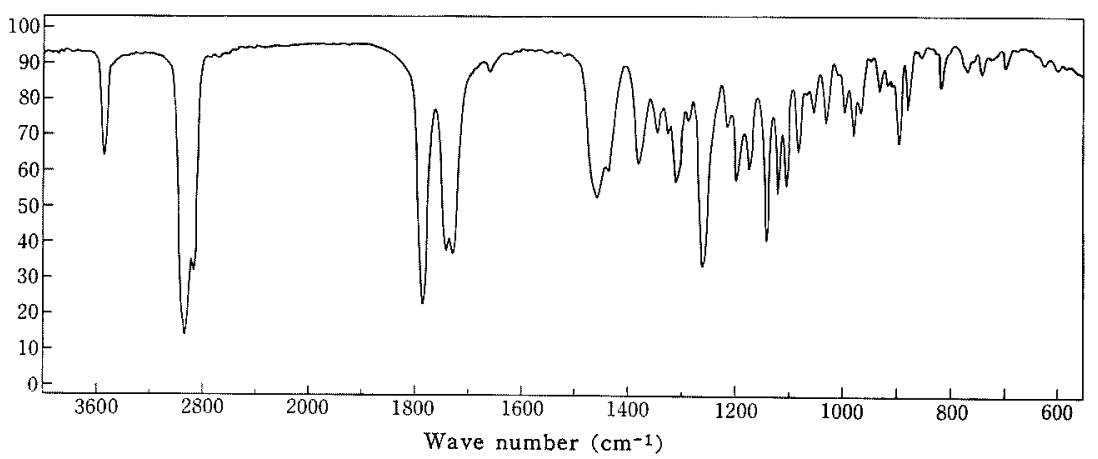

FIG. 4. IR Spectrum of $\mathrm{GA}_{21}$ Methyl Ester (nujol).

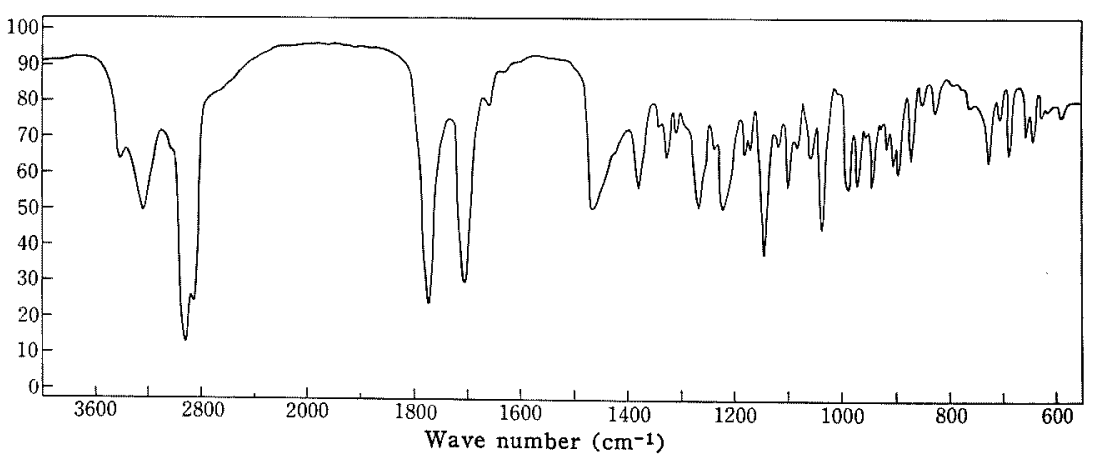

FIG. 5. IR Spectrum of $\mathrm{GA}_{22}$ (nujol). 


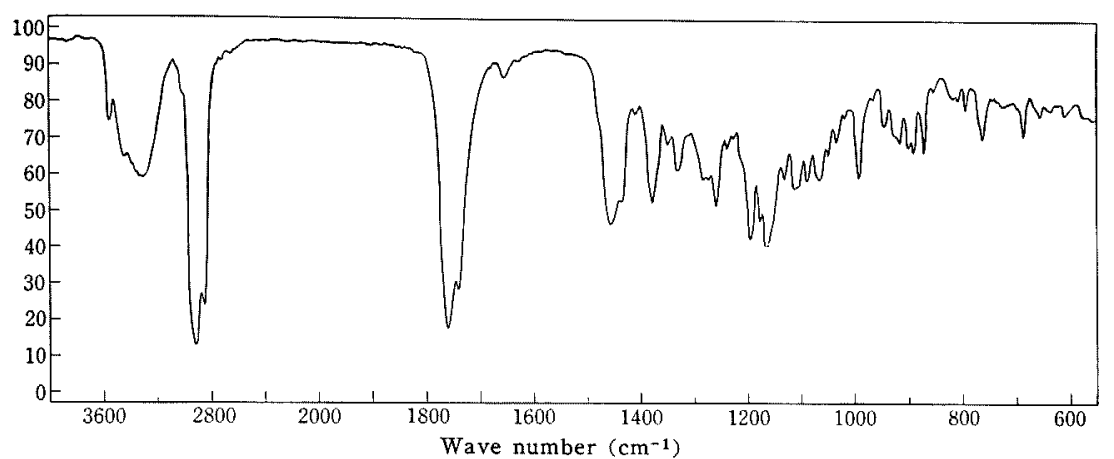

FIG. 6. IR Spectrum of GA $A_{22}$ Methyl Ester (nujol).

proposal of MacMillan and Takahashi." The IR spectra of $\mathrm{GA}_{21}, \mathrm{GA}_{22}$ and their methyl esters are shown in Figs. $3 \sim 6$. As reported in the preliminary report ${ }^{3}$ the structures I and II have been assigned to $\mathrm{GA}_{21}$ and $\mathrm{GA}_{22}$
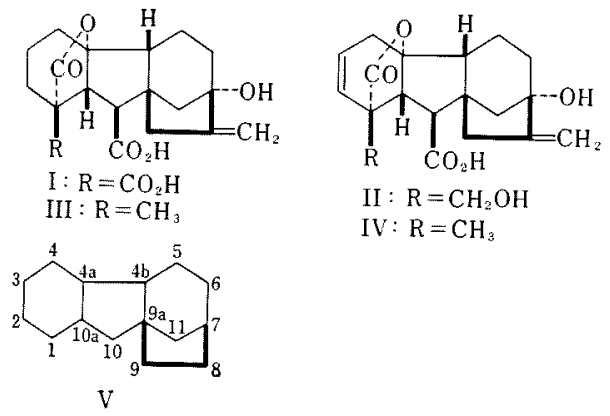

$\mathrm{II}: \mathrm{R}=\mathrm{CH}_{2} \mathrm{OH}$

IV: $\mathrm{R}=\mathrm{CH}_{3}$

respectively. The details of the structural elucidation will be described in the succeeding paper.

Biological activities of the new gibberellins were examined by the use of dwarf maize mutants $d_{1}$ and $d_{5}$, rice, cucumber and dwarf pea (Progress No. 9). As shown in Table I, $\mathrm{GA}_{21}$ exhibited very weak but evident effect on the $d_{1}$ and $d_{5}$ maize mutants. The application of $100 \mu \mathrm{g}$ of $\mathrm{GA}_{21}$ per plant of both mutants resulted in stem elongation only comparable to that caused by $1 \mu \mathrm{g}$ of $\mathrm{GA}_{3}$. When $\mathrm{GA}_{22}$ was applied to $d_{1}$ and $d_{5}$ mutants at a

4) J. McMillan and N. Takahashi, Nature, 217, No. 5124,170 (1968). dose of $1 \mu \mathrm{g}$ per plant, stem elongation was about $200 \%$ of the control.

$\mathrm{GA}_{21}$ showed no effect on rice seedlings at $10 \mathrm{ppm}$, while $\mathrm{GA}_{22}$ caused $130 \%$ elongation at $0.3 \mathrm{ppm}$. The growth of cucumbers was not affected by both compounds. On dwarf peas $\mathrm{GA}_{21}$ exhibited very weak activity, elongation being $130 \%$ of the control even at a dosage of $100 \mu \mathrm{g}$ per plant. $\mathrm{GA}_{22}$, on the other hand, caused nearly $200 \%$ elongation at $0.01 \mu \mathrm{g}$.

The action spectrum of $\mathrm{GA}_{22}$, in which activities on rice and cucumber are extremely lower than those on dwarf maize mutants, might be characteristic of gibberellins bearing a hydroxyl at C-7 but not at C-2 on the gibbane ring (V). ${ }^{5}$ It is noteworthy that $\mathrm{GA}_{21}$ and $\mathrm{GA}_{22}$ with a carboxyl and a hydroxymethyl, respectively, instead of a methyl at C-1 show gibberellin activity. It has been imagined so far that the C-1 methyl is essential for gibberellins to show biological activity, but this hypothesis should be revised hereafter. The structural features of these gibberellins may suggest the catabolic pathways of $\mathrm{GA}_{20}$ (pharbitis gibberellin) (III) and $\mathrm{GA}_{5}$ (IV) which have been confirmed to exist in immature seeds of higher plants such as morning glory.

5) N. Murofushi, N. Takahashi, T. Yokota and S. Tamura, Agr. Biol. Chem., 32, 1239 (1968). 
TABLE I. GROWTH-PROMOTING ACtivities OF $\mathrm{GA}_{21}, \mathrm{GA}_{22}$ AND $\mathrm{GA}_{3}$ ON HIGHer Plants

A) Activity on dwarf maize mutants, $d_{1}$ and $d_{5}$

\begin{tabular}{|c|c|c|c|c|}
\hline \multirow{2}{*}{ Mutant } & \multirow{2}{*}{$\begin{array}{l}\text { Dosage, } \\
\mu \mathrm{g} / \text { plant }\end{array}$} & \multicolumn{3}{|c|}{$\begin{array}{l}\text { Sum of } 1 \text { st and } 2 \text { nd leaf-sheath } \\
\text { lengths, } \mathrm{mm}\end{array}$} \\
\hline & & $\mathrm{GA}_{21}$ & $\mathrm{GA}_{22}$ & $\mathrm{GA}_{3}$ \\
\hline \multirow{4}{*}{$d_{1}$} & 100 & 88 & - & - \\
\hline & 10 & 70 & 94 & - \\
\hline & 1 & 52 & 82 & 102 \\
\hline & 0.1 & - & 55 & 77 \\
\hline \multirow{4}{*}{$d_{5}$} & 100 & 77 & - & - \\
\hline & 10 & 57 & 111 & - \\
\hline & 1 & 39 & 79 & 110 \\
\hline & 0.1 & - & 42 & 68 \\
\hline
\end{tabular}

Control: $d_{1}, 41 \mathrm{~mm} ; d_{5}, 31 \mathrm{~mm}$

B) Activity on rice (Norin No. 1)

Dosage, ppm

Length of 2nd leaf-sheath, $\mathrm{mm}$

$\begin{array}{rccc}10 & 32 & - & - \\ 3 & 31 & 49 & - \\ 1 & 30 & 47 & 67 \\ 0.3 & - & 41 & 53\end{array}$

Control: $30 \mathrm{~mm}$

C) Activity on cucumber

$\begin{array}{rccc}\begin{array}{c}\text { Dosage, } \\ \mu \text { g/plant }\end{array} & \overbrace{\mathrm{A}_{21}}^{\text {Length of hypocotyl, }} & \mathrm{Gm} \\ 100 & 37 & - & \mathrm{GA}_{22} \\ 10 & 39 & - & - \\ 1 & 35 & 34 & 63 \\ 0.1 & - & 39 & 39\end{array}$

Control: $37 \mathrm{~mm}$

D) Activity on dwarf pea (Progress No. 9)

\begin{tabular}{cccc}
$\begin{array}{c}\text { Dosage, } \\
\mu \mathrm{g} / \mathrm{plant}\end{array}$ & \multicolumn{3}{c}{ Length of whole stem, $\mathrm{mm}$} \\
100 & $\mathrm{GA}_{21}$ & $\mathrm{GA}_{22}$ & $\mathrm{GA}_{3}$ \\
10 & 60 & - & - \\
1 & 64 & - & - \\
0.1 & 51 & 135 & - \\
0.01 & - & 90 & - \\
Con & - & 73 & 119
\end{tabular}

Control: $41 \mathrm{~mm}$

\section{EXPERIMENTAL}

Thin layer chromatography

Thin layer chromatography was conducted by the use of Silica gel-G (Merck) and a benzene-butanolacetic acid mixture $(70: 25: 5, \mathrm{v} / \mathrm{v})$. Gibberellins on the chromatograms were detected as fluorescent spots under ultraviolet light after spraying with $70 \%$ sulfuric acid and heating at $100^{\circ} \mathrm{C}$ for $10 \mathrm{~min}$. $R f$ values of spots I, II and III were 0.2 (cobalt blue), 0.35 (blue) and 0.65 (blue), respectively.

\section{Isolation of $G A_{21}$ and $G A_{22}$}

a) Separation of acidic fraction. Nineteen kilograms of immature seeds (each seed, $0.8 \sim 3.0 \mathrm{~g}$ in weight) were repeatedly extracted with acetone by the use of a blender, and the combined extracts were concentrated under reduced pressure. The resulting aqueous residue was extracted at $\mathrm{pH} 2.5$ with ethyl acetate, which was further extracted with aqueous sodium bicarbonate. The aqueous solution was acidified and re-extracted with ethyl acetate to give the acidic fraction. Evaporation of the solvent afforded a biologically active gum $(10.8 \mathrm{~g})$.

b) Countercurrent distribution. The acidic fraction was partitioned between $500 \mathrm{ml}$ each of ethyl acetate and phosphate buffer ( $1 \mathbf{M}, \mathrm{pH} 5.5)$, eleven transfers countercurrent distribution being conducted. Organic and aqueous phases of fractions No. $2 \sim 10$ showing activity were separated, and the combined buffer phases were extracted with ethyl acetate. All the ethyl acetate solutions were combined and concentrated to afford a solid $(5.7 \mathrm{~g})$.

c) Silicic acid adsorption chromatography. The acidic solid was extracted with two $10 \mathrm{ml}$ portions of hot ethyl acetate to separate soluble and insoluble matters. The combined extracts were chromatographed through a column of silicic acid (Mallincrodt, 60 g), which was then eluted with benzene-ethyl acetate mixtures. The content of ethyl acetate was increased stepwise by $5 \%$ for every $200 \mathrm{ml}$ of eluant. From eluates with benzene-ethyl acetate $(45: 55 \sim 25: 75, v / v)$, an active solid $(890 \mathrm{mg}$ ) was obtained.

d) Partition chromatography. Sephadex G-50 (30 g) was treated with $150 \mathrm{mg}$ of phosphate buffer $(1 \mathrm{M}$, $\mathrm{pH}$ 5.4) and packed into a column with butanol saturated with the phosphate buffer. The active solid obtained after silicic acid adsorption chromatography was dissolved in butanol and poured onto the column. Then the column was eluted with butanol saturated with phosphate buffer, and $15 \mathrm{ml}$ of eluate was collected for each fraction. On evaporation of the solvent 
fractions No. $4 \sim 8$ afforded active crystals. Recrystallization from ethanol-hexane gave $28 \mathrm{mg}$ of pure $\mathrm{GA}_{22}$ melting at $213 \sim 214^{\circ} \mathrm{C}$. It is soluble in methanol and ethanol, and sparingly soluble in acetone, ethyl acetate and water. $\nu_{\mathrm{max}}^{\text {Nujol }} \mathrm{cm}^{-1}: 3380,3240,1770,1709,1670$, 1643, 892.

Fractions No. 19 48 afforded another active crystals. Recrystallization from ethanol-chloroform-hexane gave $241 \mathrm{mg}$ of pure $\mathrm{GA}_{21}$ melting at $244 \sim 246^{\circ} \mathrm{C}$. It is soluble in methanol and ethanol, and sparingly soluble in acetone, ethyl acetate and water. $\nu_{\text {max }}^{\mathrm{Nujol}} \mathrm{cm}^{-1}: 3280$, 2520 (broad), 1779, 1730, 1682, 877.

When the same procedure was applied to the ethyl acetate-insoluble fraction separated in $\varepsilon$ ), additional $24 \mathrm{mg}$ of pure $\mathrm{GA}_{21}$ was obtained.

\section{Bioassay.}

The growth-promoting activities were tested in the same manner as in the case of $\mathrm{GA}_{19}$ (bamboo gibberellin) ${ }^{6}$ ) using dwarf maize (Zea mays L., dwarf mutants $d_{1}$ and $d_{5}$ ), rice (Oryza sativa L. cv. Norin No. 1), cucumber (Cucumis sativus L.) and dwarf pea (Pisum sativum, cr. Progress No. 9).

Acknozeledgements. The authors with to express their thanks to Dr. Y. Sumiki, Emeritus Professor of The University of Tokyo, for his interest and encouragement. They are also grateful to Professors K. Kawate and $\mathrm{K}$. Tsunoda of this University for the cultivation of sword bean and Professor B. O. Phinney of University of California for the supply of dwarf maize seeds.

6) S. Tamura, N. Takahashi, N. Murofushi and J. Kato, Plant and Cell Phisiol., 7, 677 (1966). 